\title{
INSIGHTS
}

\section{Hiding in plain sight}

\author{
Michele Kong ${ }^{1}$ \\ Pediatric Research (2022) 91:709; https://doi.org/10.1038/s41390-021-01498-3
}

Physicians are a unique group of individuals. Our profession trains us to perform at a very high standard, even when placed in less than ideal conditions. We pay little regard to the long waking hours, often fueled just by coffee. We have the ability to focus on the crisis at hand, whether it is resuscitating a child in shock or performing a lifesaving procedure, regardless of our personal situation outside the hospital.

I knew that I wanted to be a doctor at a young age. Growing up in a small fishing village in Sarawak, higher education was not a guarantee. But I had ambition, discipline, and willpower. These attributes were the pillars of my journey as I chased my dream across the world. High school in Australia, medical school in Canada, followed by pediatric residency training, and finally critical care fellowship in the United States. Even as I became an ultrarunner, these assets served me well in my training and carried me to the finish line of my 100-mile race. I was unafraid of challenges, and my mind and body never failed me.

This was until the summer of 2020.

I woke up feeling disconnected from my body. It was mine, but I had no control over it. My leg felt heavy, numb, and tingly, with shooting pain that came and went without warning. My face did funny things. The world spun as if I was riding on a carousel. I initially ignored the symptoms, coming up with what I thought were reasonable explanations. Post-call fatigue. Twisted ankle from getting caught under the root on the trail. I kept pushing forward and yet, no matter how hard I willed them to go away, the symptoms persisted. No amount of discipline and willpower was going to get me out of this situation. Numerous testing ensued. My brain magnetic resonance imaging lit up in all the wrong spots, revealing the culprit of my symptoms. First came grief, then anger at my body for failing me, and with my brain for not being able to push through. I was not willing to accept the diagnosis, nor admit to myself that this was now my new norm. I told no one, except for a handful of peers who had to cover my intensive care unit service weeks. I did not want sympathy, and for people to see me differently. To be seen as less than a whole. My mantra had always been "mind over matter". Deep down, I was fearful, and to have no control of when and what my body did was paralyzing.

These feelings of fear and uncertainty were magnified as the world and health care system grappled with the Coronavirus disease 2019 (COVID-19) pandemic as it raged through our communities. As intensivists, we had to learn how to take care of critically ill children presenting with this novel disease. We started noting the rapid appearance of the multisystem inflammatory syndrome in children, a phenomenon that seems to primarily target our young patients. We mastered the most effective way to don and doff our personal protective equipment. Mask, face shield, eye goggles, surgical hats, and other protective gears became the normal routine, meant to protect ourselves and our patients. For me, these equipments also became part of my defense arsenals, allowing me to hide my disability. Every so often, the suddenness and intensity of my facial contractures would make me pause mid-sentence. But to the outside world, nothing was amiss. Wearing a mask at all times meant that no one saw the asymmetry in my face. With glasses and surgical caps, I looked no different. Zoom meetings provided the perfect refuge with the video off and allowed for full participation. Social distancing and no group gatherings immediately meant isolation from the crowd. Something that was welcomed as it also meant no questions from family and friends, and no explanations necessary.

Without knowing it, I became an expert in hiding in plain sight. But hiding does not lead to awareness and acceptance. While I did not choose to have this illness, I can choose how I face the challenges it brings. While I have no control on a daily basis on what I might physically feel or control over how and if the illness will progress, I realized that I can control how I make sense of the circumstances. There are low moments when everything feels impossibly hard. But in truth, these low moments are part of the story that adds to the depth and scope of my identity as a physician, partner, mother, daughter, sister, and friend. Slowly, I began to share my story. I shared it with my family and friends. I shared it with my patients, that to some level I understand their fears, and what it feels to have uncertainty or to not be in control. Life is unpredictable, and we owe it to ourselves and our loved ones to make the most out of the time that we have been allotted. It is not always easy, but in the end, perhaps sharing our stories is all that we have.

\section{ADDITIONAL INFORMATION}

Competing interests: The author declares no competing interests.

Publisher's note Springer Nature remains neutral with regard to jurisdictional claims in published maps and institutional affiliations.

\footnotetext{
The University of Alabama at Birmingham, Birmingham, AL, USA
}

Correspondence: Michele Kong (mkong@peds.uab.edu)

Received: 4 March 2021 Accepted: 11 March 2021

Published online: 31 March 2021 